\title{
Urothelial cancer and the diagnosis of subsequent malignancies
}

\author{
Deepak K. Pruthi, MD; ; Zoann Nugent, PhD; ${ }^{*}$ Piotr Czaykowski, MD; ${ }^{\xi_{*}}$ Alain A. Demers, PhD ${ }^{\dagger *}$
}

*Department of Urology, University of Manitoba, Winnipeg, MB; †Department of Epidemiology and Cancer Registry, CancerCare Manitoba, Winnipeg, MB; §Department of Medical Oncology and Hematology, CancerCare Manitoba, Winnipeg, MB; * Department of Community Health Sciences, University of Manitoba, Winnipeg, MB

Cite as: Can Urol Assoc J 2013;7:E57-E64. http://dx.doi.org/10.5489/cuaj.234

\section{Abstract}

Purpose: We examine the likelihood of a second primary malignancy diagnosis following the diagnosis of urothelial cancer.

Methods: We identified subjects from the Manitoba Cancer Registry diagnosed with urothelial cancer between April 1, 1985 and December 31, 2007. Data were collected on all subsequent new cancer diagnoses. Standardized incidence ratios (SIRs) were calculated for each major cancer type, matched with the general population by age, sex and period. Further analysis was undertaken stratifying by morphology and invasiveness. The results in males were examined with and without prostate cancer. A competing risk model was used to analyze the data controlling for death.

Results: Of the 4412 included urothelial cancer cases, 712 patients (16.1\%) subsequently developed a second primary malignancy. Risks were highest within 1 year of diagnosis persisting for 5 years. This risk was highest in males aged less than 70 (SIR $=6.25 ; 95 \%$ Confidence Interval [CI] 5.08-7.04). Overall, the risk was similar between the sexes (female SIR: 1.30, CI 1.09-1.54; males $1.42, \mathrm{CI}$ 1.31-1.54; males excluding prostate SIR: $1.22 \mathrm{CI} 1.11-1.35)$. There was an increased relative risk for developing a second primary for cancers of the kidney (male), lung, breast (female) and prostate. Papillary cancers were associated with increased relative risk of developing lung, prostate, and breast (female and male) cancer. In the competing risks model, patients diagnosed with a papillary or in situ urothelial cancer were more likely to be diagnosed with a second primary than non-papillary and invasive disease, respectively. Conclusions: Those diagnosed with urothelial cancer have an increased probability of having a second primary cancer detected within the subsequent 5 years, even when prostate cancer is excluded. Papillary tumours in particular may provide a warning for subsequent malignancy.

\section{Introduction}

Studies have described the relationship between initial cancer diagnoses and diagnosis of subsequent primaries. ${ }^{1-4}$
Multiple primaries, as defined by the International Agency for Research on Cancer (IARC), are those cancers which develop in several primary sites that are not an extension, recurrence nor metastasis of each other. Multiple primaries also include tumours arising from the same site but with different morphologies. ${ }^{5}$

Urothelial malignancies are unique and encompass cancers of the transitional cell epithelium found in the bladder, renal pelvis, and ureters (or BRPU). Despite a relatively stable incidence rate, urothelial cancers remain among the most frequently diagnosed cancers in Canada. ${ }^{6}$ This is concerning as bladder cancer, accounting for the vast majority of BPRU cancers, has been highly correlated with the diagnosis of subsequent primary malignancies of other sites. ${ }^{7,8}$ Indeed, a report using data from Surveillance Epidemiology and End Results (SEER) demonstrated the development of subsequent primary cancers in as many as $16 \%$ of bladder cancer patients - the highest percentage of any cancer site (except non-melanoma skin cancer and cancer of the upper aerodigestive tract). ${ }^{9}$

Urothelial cancers often present multifocally, complicating the ascertainment of second primary malignancies because newly identified BPRU cancers may be new manifestations of the original urothelial cancer (unless they have different histologies). This should be accounted for in calculations.

Knowledge of clustering malignancies should increase the likelihood of early detection of subsequent cancers and ultimately improve patient outcomes. The objective of the present study was to determine the risk of being diagnosed with a second primary malignancy subsequent to the diagnosis of a urothelial cancer, including histopathologic subanalysis. We sought to identify commonly diagnosed specific second primaries and to determine if there was an association by histology, age or sex. Furthermore, because of the frequent co-diagnosis of urinary bladder cancers and prostate cancer, and the fact that prostate-specific antigen (PSA)-screening often detects clinically insignificant prostate 
Pruthi et al.

cancer, this study examines the risks of second malignancy both including and excluding prostate cancer.

\section{Methods}

All Manitoban subjects diagnosed with their first BRPU cancer (including bladder cancer in situ) between April 1, 1985 and December 31, 2007 were identified from the population-based Manitoba Cancer Registry. Developed in 1937, the Manitoba Cancer Registry became population-based in 1956. Cancer reporting is mandated by law in Manitoba, Canada, and information on all potential new cases must be forwarded to the Registry. The Manitoba Cancer Registry has been rated highly by the North American Association of Central Cancer Registries. ${ }^{10}$

The following ICD-10 histopathologic morphology codes were used: papillary transitional cell carcinoma (TCC) (ICD0/3 8130/3), TCC (8120/3), papillary TCC, non-invasive (8130/2), TCC in situ (8120/2) and basaloid carcinoma (8123/3); these make up more than $90 \%$ of the BRPU cancers in this study. Both invasive and non-invasive cancers can be papillary in morphology.

Autopsy and death certificate-only diagnoses were excluded from the analysis. Recurrent BPRU cancers or any second primary cancers from any BRPU site (with congruent histology) were excluded. Due to their small numbers, urothelial cancers of the proximal urethra and prostate were not included. In addition, non-melanoma skin cancers were not considered. Patients previously diagnosed with a nonBPRU cancer were excluded in this study. Similarly, patients were excluded if the second primary diagnosis was within 30 days of the BPRU diagnosis.

Second primary cancers were identified among the subjects with a prior diagnosis of BPRU cancer using ICD-10 histopathologic morphology codes and ICD-0-3 topography codes abstracted from pathology reports. The first analysis included all second primaries post-BPRU cancer diagnosis, while the second analysis, for males, excluded prostate cancers entirely from study population and the reference population. Upon the diagnosis of BPRU cancer, the time (person-years) until the first diagnosis of a second primary malignancy, death, or the December 31, 2007 date was recorded. Patients who died within 30 days of urothelial cancer diagnosis and patients who were diagnosed with a second cancer within 30 days were excluded from analysis to mitigate an ascertainment bias. We were unable to account for those who emigrated outside Canada. If the emigrants remained within Canada and subsequently died, death information was available and incorporated into the calculation.

The standard incidence ratio (SIR) was calculated by taking the ratio of observed cancers in the urothelial cancer patients to the expected number of cancers calculated from person-years of follow-up and Manitoba rates for that age, sex and year. The expected number of cancers was obtained by comparing the cancer incidence (excluding urothelial cancer and non-melanoma skin cancer) in the Manitoba population (from anonymized age/sex data for people registered to receive healthcare from Manitoba Health) matched by 5-year age band, sex and time period multiplying this by the person-years. The age specific incidences are available at our cancer centre.

The SIRs were compared by sex, age group and by the length of time after initial urothelial cancer diagnosis. Age at BPRU cancer diagnosis was presented in three categories: (1) under 70; (2) age 70 and above; and (3) all ages. We chose age 70 as the cutoff point because 72 is the average age of BPRU cancer diagnosis.

The follow-up time was divided into 5 categories: (1) 31 days to 1 year; (2) 1 to 5 years; (3) 5 to 10 years; (4) 10 years or longer; and (5) total time from first primary cancer diagnosis. The $95 \%$ confidence intervals $(\mathrm{Cl})$ were calculated assuming that the second primaries follow a Poisson distribution.

In addition, given that death would preclude the development of a second malignancy, a competing risk analysis was conducted using death as the competing risk to examine possible predictors of second cancer diagnosis. ${ }^{11}$

Database interrogation was performed using SAS 9.1 (SAS Institute, Cary, NC).

\section{Results}

Of the 4686 cases of BPRU cancer diagnosed, 122 patients died within 30 days, while a further 140 were diagnosed with a second cancer within the same time period. Twelve patients had their Manitoba Health coverage cancelled resulting in 4412 cases included in the study (Table 1). The median age-at-diagnosis was 72 (inter-quartile range [IQR]: 62-80) for females and 71 (IQR: 62-78) for males; 10 cases of BPRU cancer occurred in those under age 30. There were 16 cases of second primary bladder cancers; these second bladder cancers were disregarded and patients were followed as outlined above. Most diagnoses (95.6\%) were cytologically/ histologically confirmed. In the 4412 subjects, 583 cases (410 males, 101 females) of second primary cancers were expected. However, 712 cases were observed resulting in second primaries diagnosed in $16.1 \%$ of cases.

Males aged $<70$ had a consistently higher SIR for developing a subsequent primary $(6.25 ; 95 \% \mathrm{CI} 5.08-7.70)$ than males aged $\geq 70$ years (SIR 2.25; 95\% Cl 1.83-2.75) within 1 year of diagnosis of first primary. This younger age group still had an excess risk 5 years after the initial diagnosis. When excluding prostate cancer, males aged $<70$ still had elevated risks within 1 year of urothelial cancer diagnosis (SIR 3.25; $95 \% \mathrm{Cl} 2.27-4.49)$. Females age $<70$ had an excess risk in the 


\begin{tabular}{|c|c|c|c|c|c|c|}
\hline \multirow[t]{2}{*}{ Variables } & \multicolumn{3}{|c|}{ No. urothelial cancers (\%) } & \multicolumn{3}{|c|}{ No. second primaries (\%) } \\
\hline & Total & Female & Male & Totalc & Female $^{c}$ & Male $^{c}$ \\
\hline Total $^{a}$ & 4412 & $1156(26)$ & $3256(74)$ & $712(16)$ & $131(11)$ & $581(18)$ \\
\hline \multicolumn{7}{|l|}{$\mathrm{Age}^{\mathrm{b}}$} \\
\hline$<70$ & 1936 (44) & 491 (42) & 1445 (44) & 336 (17) & $57(12)$ & 279 (19) \\
\hline$\geq 70$ & $2476(56)$ & $665(58)$ & $1811(56)$ & $376(15)$ & $74(11)$ & $302(17)$ \\
\hline \multicolumn{7}{|c|}{ Time period urothelial diagnosis } \\
\hline $1984-1991$ & $1196(27)$ & $311(27)$ & $885(27)$ & $213(19)$ & $45(14)$ & $186(21)$ \\
\hline 1992-1996 & $907(21)$ & $255(22)$ & $652(20)$ & $202(22)$ & $48(19)$ & $154(24)$ \\
\hline 1997-2001 & $1044(24)$ & $248(21)$ & 796 (24) & $167(16)$ & $24(10)$ & $143(18)$ \\
\hline 2002-2007 & $1265(29)$ & $342(30)$ & $923(28)$ & $112(9)$ & $14(4)$ & $98(11)$ \\
\hline \multicolumn{7}{|l|}{ Disease type } \\
\hline In situ bladder & $1126(26)$ & $276(24)$ & $850(26)$ & $165(15)$ & $33(12)$ & $132(16)$ \\
\hline Invasive bladder & $3003(68)$ & $770(67)$ & $2233(69)$ & $516(17)$ & $84(11)$ & $432(19)$ \\
\hline Invasive renal pelvis & $202(5)$ & $80(7)$ & $122(4)$ & $19(9)$ & $8(10)$ & $11(9)$ \\
\hline Invasive ureter & $81(2)$ & $30(3)$ & $51(2)$ & $12(15)$ & $6(20)$ & $6(12)$ \\
\hline Transitional cell carcinoma & $1011(23)$ & $260(22)$ & $751(23)$ & $150(15)$ & $22(8)$ & $128(17)$ \\
\hline Adenocarcinoma & $50(1)$ & $15(1)$ & $35(1)$ & $5(10)$ & $0(0)$ & $5(14)$ \\
\hline Squamous cell carcinoma & $67(2)$ & $28(2)$ & $39(1)$ & $8(11)$ & $3(11)$ & $5(13)$ \\
\hline Papillary transitional & $3078(70)$ & $781(68)$ & $2297(71)$ & $526(17)$ & $101(13)$ & 425 (18) \\
\hline Other & $206(5)$ & $72(6)$ & $134(4)$ & $23(11)$ & $5(7)$ & $18(13)$ \\
\hline
\end{tabular}

first year following diagnosis (SIR 2.42; 95\% Cl 1.11-4.59), but this risk normalized 1 to 5 years after diagnosis (SIR 1.32; $95 \% \mathrm{Cl}$ 0.78-2.08). The $\geq 70$ age group had an elevated risk within the first year of diagnosis (SIR 3.25; 95\% Cl 2.27-4.49) but this risk normalized later, between 5-10 years post-BPRU cancer diagnosis (SIR 0.77; 95\% Cl 0.53-1.09).

When examining the overall SIRs (Table 2), it is clear that there was no significant age-specific difference in risk for diagnosis of second primaries among females; however, among males the 95\% confidence intervals do not overlap between the under and over 70 age groups when prostate cancer is included. In addition, patients of either sex, diagnosed with a papillary tumour and males with TCC had an increased relative risk of developing a second primary when compared to their respective reference populations.

Table 3 shows the risk for developing selected second primaries from the present study and from two larger studies. ${ }^{8,9}$ The analysis reveals an increased risk of diagnosis of kidney

\begin{tabular}{|c|c|c|c|c|c|c|c|}
\hline & & Overall & $1985-2007$ & & Age $<70$ & & Age $\geq 70$ \\
\hline \multirow{4}{*}{ Female } & & Count & SIR $(95 \% \mathrm{CI})$ & Count & SIR (95\% CI) & Count & SIR $(95 \% \mathrm{CI})$ \\
\hline & All & 131 & $1.30(1.09-1.54)$ & 57 & $1.26(0.97-1.64)$ & 74 & $1.33(1.06-1.67)$ \\
\hline & Papillary & 101 & $1.32(1.09-1.60)$ & 44 & $1.22(0.91-1.64)$ & 57 & $1.41(1.09-1.83)$ \\
\hline & TCC & 22 & $1.15(0.72-1.74)$ & 9 & $1.32(0.60-2.50)$ & 13 & $1.05(0.56-1.80)$ \\
\hline \multirow[t]{3}{*}{ Male including prostate } & All & 581 & $1.42(1.31-1.54)$ & 279 & $1.61(1.43-1.81)$ & 302 & $1.28(1.14-1.43)$ \\
\hline & Papillary & 425 & $1.33(1.21-1.46)$ & 200 & $1.43(1.24-1.64)$ & 225 & $1.25(1.09-1.42)$ \\
\hline & $\mathrm{TCC}$ & 128 & $1.77(1.49-2.10)$ & 63 & $2.29(1.79-2.93)$ & 65 & $1.45(1.14-1.85)$ \\
\hline \multirow[t]{3}{*}{ Male excluding prostate } & All & 404 & $1.22(1.11-1.35)$ & 177 & $1.31(1.13-1.52)$ & 227 & $1.16(1.02-1.32)$ \\
\hline & Papillary & 304 & $1.19(1.06-1.33)$ & 135 & $1.25(1.06-1.48)$ & 169 & $1.15(0.98-1.33)$ \\
\hline & TCC & 76 & $1.27(1.01-1.59)$ & 32 & $1.47(1.01-2.08)$ & 44 & $1.15(0.86-1.55)$ \\
\hline
\end{tabular}

*Bolded text indicates statistical significance.

TCC: transitional cell carcinoma; SIR: standardized incidence ratios; $\mathrm{Cl}$ : confidence interval. 
(male), lung, breast (female) and prostate. Those diagnosed with papillary tumours and TCC had increased relative risks of developing lung cancer and prostate cancer. Moreover, diagnosis of papillary tumour was found to be associated with an increased risk of diagnosis for breast cancer for both females and males.

Generally, the relative risk of a diagnosis of a second primary diminished as time from urothelial cancer diagnosis increased (Table 4). Female breast cancer was more likely diagnosed between 1 to 5 years than within the first year of diagnosis of a BPRU cancer, and the relative risk for lung cancer diagnosis remained elevated up to 5 to 10 years from the original primary diagnosis.
There were no sex- or age-based differences in the risk of being diagnosed with a second primary (Table 5). However, patients with papillary and in situ tumours were more likely to have a second cancer diagnosis than non-papillary and invasive cancers, respectively.

Fig. 1 and Fig. 2 show the accumulation of second primaries among patients previously diagnosed with a BPRU cancer using competing risk analysis. The curves suggest that within the first few years following the diagnosis, those diagnosed with papillary and in situ cancer accumulated second primaries more rapidly than those diagnosed with non-papillary and invasive cancers, respectively.

Table 3. Standard incidence ratios for selected second primaries 31 days post bladder cancer diagnosis with comparisons to two large studies ${ }^{a}$

\begin{tabular}{|c|c|c|c|c|c|c|}
\hline Site & Sex & Type & $\begin{array}{l}\text { Second } \\
\text { primaries }\end{array}$ & SIR (95\% CI) & SEER data ${ }^{b}$ SIR & $\begin{array}{l}\text { Swedish Studyc } \\
\text { SIR (95\% CI) }\end{array}$ \\
\hline \multirow[t]{6}{*}{ Kidney } & Female & All & 2 & $0.90(0.11-3.26)$ & $17.79^{d, e}$ & $0.60(0.37-0.98)$ \\
\hline & & Papillary & 2 & $1.18(0.14-4.27)$ & & \\
\hline & & TCC & 0 & $0(0-7.22)$ & & \\
\hline & Male & All & 22 & $1.75(1.10-2.65)$ & $11.08^{\mathrm{d}, \mathrm{e}}$ & $1.38(1.02-1.79)$ \\
\hline & & Papillary & 15 & $1.52(0.85-2.51)$ & & \\
\hline & & TCC & 4 & $1.83(0.50-4.68)$ & & \\
\hline \multirow[t]{6}{*}{ Lung } & Female & All & 35 & $2.35(1.69-3.27)$ & $2.14^{\mathrm{e}}$ & $3.32(2.76-3.99)$ \\
\hline & & Pap & 24 & 2.09 (1.34-3.11) & & \\
\hline & & TCC & 8 & $2.99(1.29-5.90)$ & & \\
\hline & Male & All & 124 & $1.65(1.39-1.97)$ & $1.54^{\mathrm{e}}$ & $2.00(1.85-2.17)$ \\
\hline & & Papillary & 93 & $1.59(1.30-1.95)$ & & \\
\hline & & TCC & 27 & $2.03(1.34-2.96)$ & & \\
\hline \multirow[t]{6}{*}{ CRC } & Female & All & 16 & $0.92(0.52-1.49)$ & $\begin{array}{l}\text { Colon }=1.05 \\
\text { Rectum }=0.99\end{array}$ & $\begin{array}{c}\text { Colon }=1.76(1.44-2.15) \\
\text { Rectum }=1.67(1.25-2.24)\end{array}$ \\
\hline & & Papillary & 14 & $1.07(0.59-1.80)$ & & \\
\hline & & TCC & 1 & $0.29(0.01-1.60)$ & & \\
\hline & Male & All & 68 & $1.03(0.82-1.31)$ & $\begin{array}{l}\text { Colon=0.99; } \\
\text { Rectum=1.01 }\end{array}$ & $\begin{array}{l}\text { Colon = } 1.21(1.09-1.34) \\
\text { Rectum }=1.22(1.06-1.41)\end{array}$ \\
\hline & & Papillary & 51 & $0.99(0.75-1.31)$ & & \\
\hline & & TCC & 12 & $1.04(0.53-1.81)$ & & \\
\hline \multirow[t]{6}{*}{ Breast } & Female & All & 39 & $1.56(1.11-2.13)$ & 0.95 & $0.98(0.85-1.13)$ \\
\hline & & Papillary & 32 & $1.67(1.14-2.36)$ & & \\
\hline & & TCC & 6 & $1.30(0.48-2.82)$ & & \\
\hline & Male & All & 3 & $3.83(0.79-11.20)$ & - & $0.95(0.39-2.29)$ \\
\hline & & Papillary & 3 & 4.92 (1.01-14.38) & & \\
\hline & & TCC & 0 & $0(0-21)$ & & \\
\hline \multirow[t]{3}{*}{ Prostate } & Male & All & 224 & $1.83(1.60-2.08)$ & $1.14^{\mathrm{e}}$ & 1.41 (1.34-1.49) \\
\hline & & Papillary & 150 & $1.57(1.34-1.84)$ & & \\
\hline & & TCC & 63 & $2.90(2.27-3.71)$ & & \\
\hline
\end{tabular}

a: This data includes the second cancers following the initial diagnosis of urothelial cancer. Patients were eliminated from the calculations once they developed their second cancer. Standard

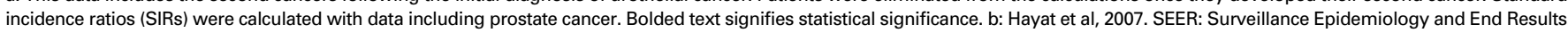
c: Bermejo et al, 2009. d: This study includes kidney, renal pelvis, ureter, and other urinary organs in this group. e: $p<0.05$.

Cl: confidence interval; TCC: transitional cell carcinoma; CRC: colorectal cancer; SIR: standardized incidence ratio. 


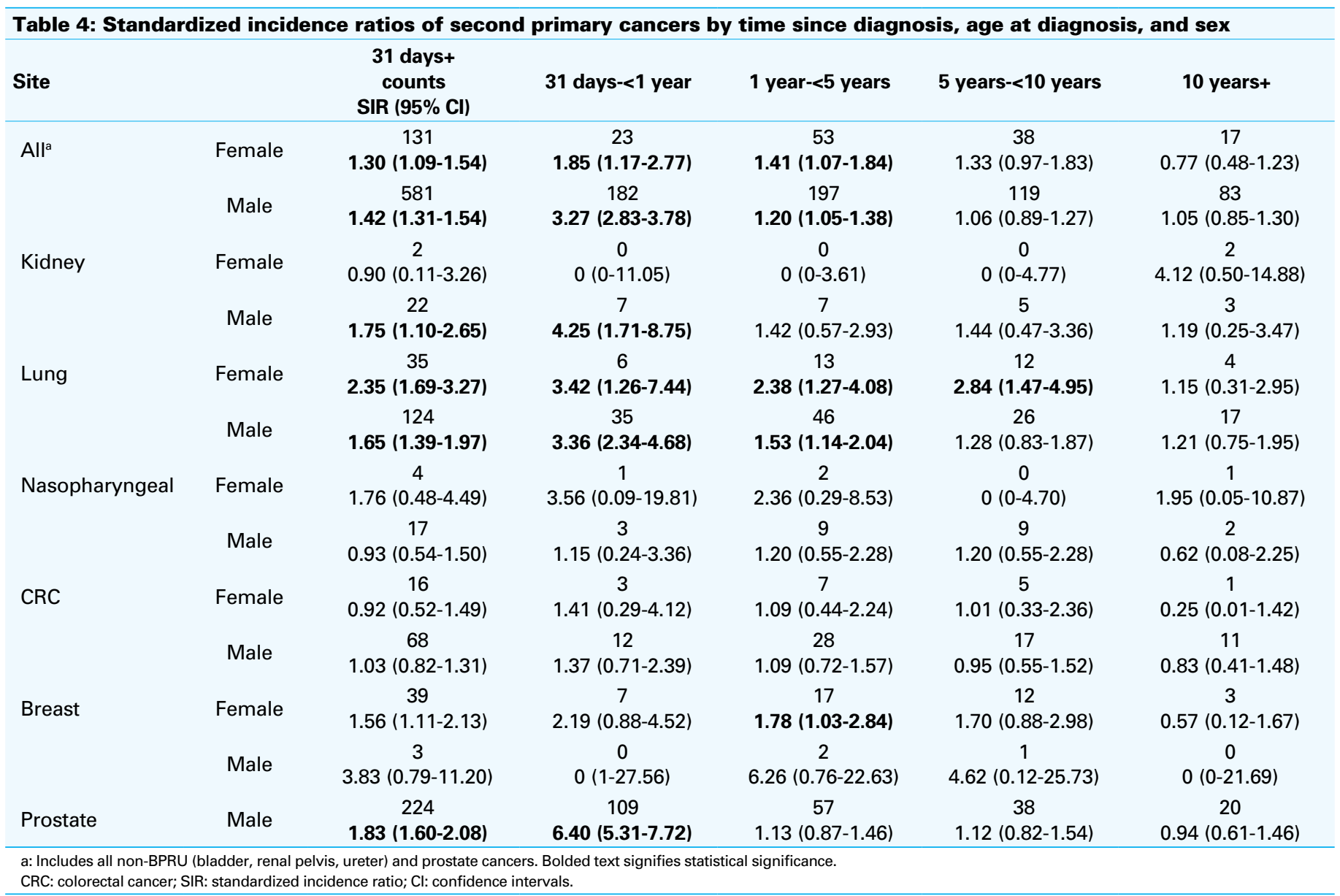

\section{Discussion}

The diagnosis of subsequent primary malignancies posturothelial cancer diagnosis is high in our study; $16.1 \%$ of BPRU cancer cases $(17.8 \%$ male and $11.3 \%$ female) were diagnosed with a subsequent primary malignancy. This percentage is congruent with other studies. ${ }^{2,9}$ The increased risk is similar for both sexes and persists up to 5 years from the initial BPRU cancer diagnosis.

The overall risk for diagnosis of a second primary cancer is greatest for males within the first year of being diagnosed with a BPRU cancer and persists for up to 5 years; beyond 10 years there is no significant elevation in risk compared with a standardized matched population. The highest increased risk is found among males aged $<70$ within 1 year of BPRU cancer diagnosis even after prostate cancer is eliminated from the data calculations. When prostate cancer is excluded from the analysis, the overall risk for developing a second primary at any time beyond 31 days after BPRU cancer diagnosis is similar to the risks among females. The cumulative risks show that a substantial number of people diagnosed with a urothelial cancer develop a second cancer. Moreover, when controlling for the competing risks of death patients with papillary and in situ tumours were more likely to be diagnosed with a second malignancy compared to non-papillary and invasive cancers, respectively.

There was an increased risk of diagnosis of kidney (male), lung, breast (female) and prostate cancer. However, the risk of female breast and female lung cancer persisted longer than the risks for male lung and prostate cancer. In addition, those diagnosed with papillary tumours and TCC had increased relative risks of developing lung cancer and prostate cancer. Interestingly papillary bladder cancer was associated with increased risk of female and male breast cancer.

Table 5. Predictors of second cancer diagnosis*

\begin{tabular}{lcc}
\hline Predictor & $\begin{array}{c}\text { Hazard ratio } \\
(\mathbf{9 5 \%} \mathbf{C l})\end{array}$ & $\boldsymbol{p}$ value \\
\hline Age $\geq 70$ vs. $<70$ & $1.02(0.86-1.21)$ & 0.81 \\
Invasive vs. in situ & $\mathbf{0 . 6 6}(\mathbf{0 . 5 3}-\mathbf{0 . 8 3})$ & $<\mathbf{0 . 0 0 1}$ \\
Male vs. female & $0.97(0.80-1.18)$ & 0.79 \\
Papillary vs. non-papillary & $\mathbf{1 . 3 8}(\mathbf{1 . 1 3 - 1 . 6 9 )}$ & $\mathbf{0 . 0 0 2}$ \\
\hline *Using a Competing Risk Model, death being the competing risk All data are compared \\
$\begin{array}{l}\text { excluding prostate cancer. Bolded text signifies statistical significance. Hazard ratio > } 1 \\
\text { implies increased risk for the predictor listed first. }\end{array}$ \\
Cl: confidence interval.
\end{tabular}




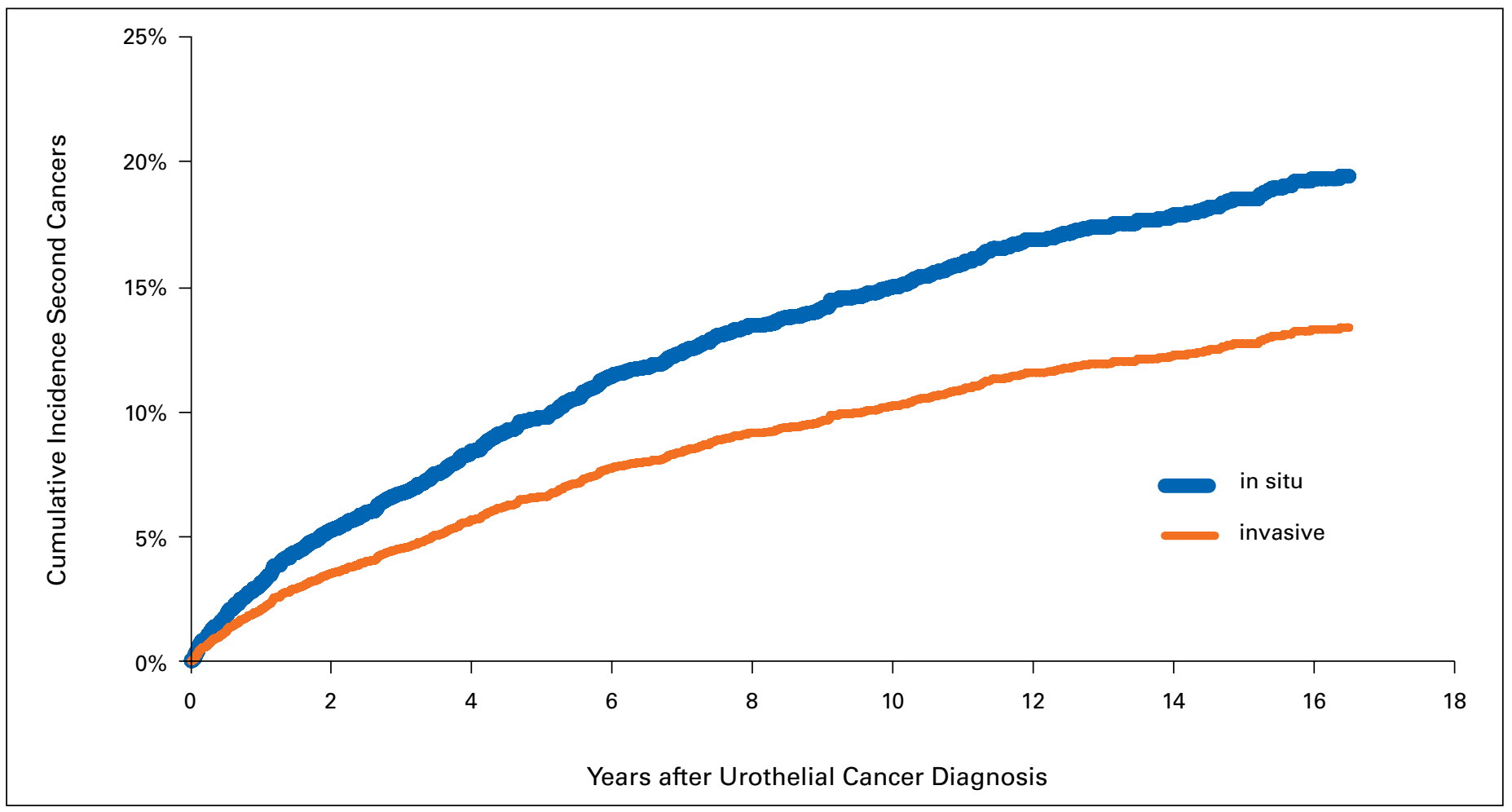

Fig. 1. Accumulation of second cancers among patients with a urothelial cancer: in situ versus invasive.

Admittedly, some of this clustering may be attributable to the well recognized link between the diagnoses of prostate cancer and bladder cancer. ${ }^{12-14}$ In this study, the overall relative risk for developing prostate cancer as a second primary was 1.83 . This elevated incidence is likely attributable to diagnostic efforts which result in the detection of pre-clinical phases of prostate cancer. ${ }^{12}$ Furthermore, the diagnosis of clinically significant prostate cancer has been complicated by the introduction of PSA-screening as many have reported over-diagnosis and over-treatment. ${ }^{15,16}$ This may be reflected in the high rate of prostate cancer in males $<70$ previously diagnosed with TCC (SIR $=4.1695 \% \mathrm{Cl} 2.90-5.79)$. As such, all second primaries within 30 days were excluded from analysis; to eliminate any possible effect, the data were re-analyzed assuming prostate cancer did not exist (neither in our patients or in the reference population).

The probability of developing a second primary may be attributed to the similar etiologies (environmental and/or genetic) implicated in the development of urothelial cancer and other cancers. Tobacco smoking is the predominant etiological agent for bladder cancer, ${ }^{17-19}$ and may account for about $30 \%$ of all female and $50 \%$ of all male bladder cancers. ${ }^{20}$ While examining the effect of smoking and secondary cancers Salminem and colleagues ${ }^{21}$ found an increased incidence of prostate, gastric and lung cancers in patients previously diagnosed with bladder cancer. Smoking is also involved in the etiology of renal, ${ }^{22}$ lung and laryngeal can- cers $^{23}$ and colorectal cancers. ${ }^{24}$

In this study, the risk of diagnosis of lung cancer was elevated and this is likely smoking-related. Males were at greater risk of diagnosis of kidney cancer and this may be attributable to a common or analogous pathogenesis. It has been postulated that smoking-related carcinogens, such as aromatic amines, are filtered by the kidneys and stored in the bladder, thus directly affecting both organs. That this potential effect was not noted among females and that there was no association with head and neck cancers may be attributable to the paucity of cases.

The increased risk of female breast cancer is more difficult to explain. Indeed, the evidence supporting the possible associations of breast cancer and tobacco smoking is conflicting. In addition, the association between papillary bladder cancer and breast cancer is unclear. To our knowledge, we are the first to show this relationship. Although colorectal cancers were common second primaries $(\geq 10 \%$ in all groups), the risk is not elevated. Aside from the possible biases in the diagnosis of prostate cancer, there may be some basis of a relationship rooted in the abnormal expression of tumour suppressor genes $\mathrm{p} 53$ and $\mathrm{Rb} .{ }^{14}$

This study is limited by the relatively small number of incident cases of urothelial cancer in a given age group, a problem accentuated among females. In addition, due to the time period of the study we were unable to assess longterm follow-up for more recent diagnoses (e.g, in 2003, 7 


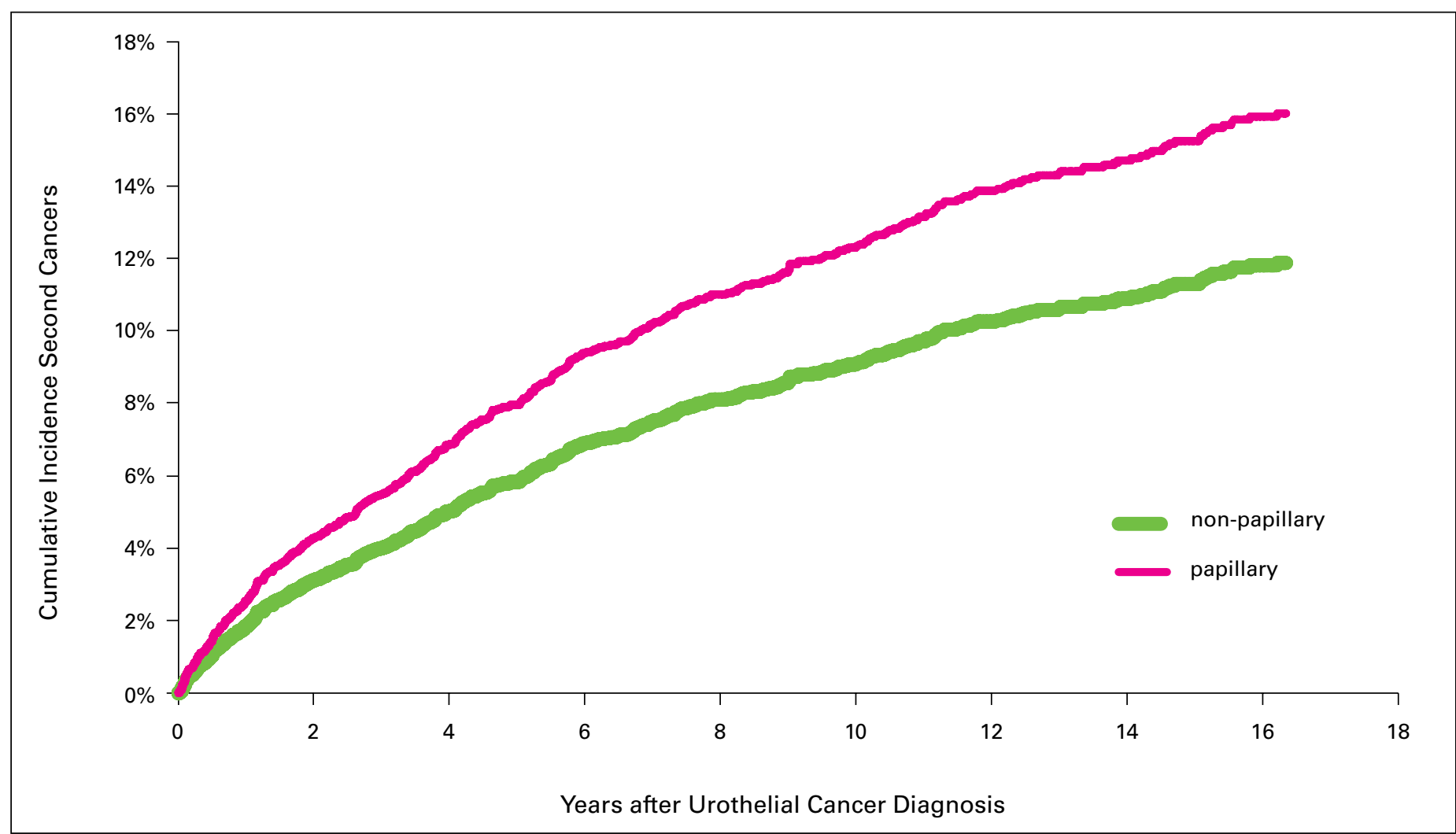

Fig. 2. Accumulation of second cancers among patients with a urothelial cancer: non-papillary versus papillary.

patients diagnosed BPRU cancer had a maximum 5-year follow-up).The subanalysis of papillary versus non-papillary cancers is also limited in that tumours with papillary architecture are frequently commented on by pathologists; however, the absence of mentioning papillary architecture does not necessarily exclude the presence of possible papillary morphology. Moreover, some of the "non-papillary" tumours may have or have had a papillary component at one point in their development. This is a systematic problem in many databases. Despite this possible bias there remains an elevated and statistically significant risk of a second primary for those patients diagnosed with papillary tumours, even in the competing risk analysis.

There are several strengths of this study. The results presented are from population-based data and we are therefore able to capture all cases of BPRU cancer and almost all second primaries. Urothelial cancers originating in the bladder, renal pelvis and ureters were considered collectively acknowledging that any subsequent cancer in the urothelial tract may not represent a true second primary. Furthermore, this is the first study to examine papillary tumours and TCC as possible markers for the diagnosis of second primary tumours. While there is potential surveillance bias, collectively, we believe these results will aid clinicians to be more vigilant of second primaries, when to expect them, and of which particular cancers to be wary.

\section{Conclusion}

The data indicate that the diagnosis of a BPRU carcinoma should put the clinician on alert for the emergence of subsequent non-urothelial cancers, particularly within the first 5 years of a BPRU cancer diagnosis.

Competing interests: None declared.

This paper has been peer-reviewed.

\section{References}

1. Beisland C, Talleraas 0 , Bakke A, et al. Multiple primary malignancies in patients with renal cell carcinoma: a national population-based cohort study. BJU Int 2006;97:698-702. http://dx.doi.org/10.1111/ j.1464-410X.2006.06004.x

2. Dong C, Hemminki K. Second primary neoplasms in 633,964 cancer patients in Sweden, 1958-1996. Int J Cancer 2001;93:155-61. http://dx.doi.org/10.1002/iic.1317

3. Frisch $M$, Olsen JH, Melbye M. Malignancies that occur before and after anal cancer: clues to their etiology. Am J Epidemiol 1994; 140:12-9

4. Richiardi L, Scelo G, Boffetta P, et al. Second malignancies among survivors of germ-cell testicular cancer: a pooled analysis between 13 cancer registries. Int J Cancer 2007;120:623-31. http://dx.doi. org/10.1002/iic.22345

5. Working Group Report. International rules for multiple primary cancers (ICD-0 third edition). Eur I Cancer Prev 2005; 14:307-8.

6. Canadian Cancer Society's Steering Committee on Cancer Statistics. Canadian Cancer Statistics 2012. Toronto, ON: Canadian Cancer Society; 2012. 
Pruthi et al.

7. Salminen E, Pukkala E, Teppo L, et al. Subsequent primary cancers following bladder cancer. Eur J Cancer 1994;30A:303-7. http://dx.doi.org/10.1016/0959-8049(94)90246-1

8. Bermejo IL, Sundquist J, Hemminki K. Bladder cancer in cancer patients: population-based estimates from a large Swedish study. Br J Cancer 2009;101:1091-9. http://dx.doi.org/10.1038/si.bic.6605325

9. Hayat MJ, Howlader N, Reichman ME, et al. Cancer statistics, trends, and multiple primary cancer analyses from the Surveillance, Epidemiology, and End Results (SEER) Program. Oncologist 2007;12:20-37. http://dx.doi.org/10.1634/theoncologist.12-1-20

10. NAACCR. Who is Certified. North American Association of Central Cancer Registries. September 19, 2012 http://www.naaccr.org/Cerrification/WhoisCertified.aspx

11. Satagopan JM, Ben-Porat L, Berwick $M$, et al. A note on competing risks in survival data analysis. $B r J$ Cancer 2004;91:1229-35. http://dx.doi.org/10.1038/si.bic.6602102

12. Heard A, Roder D, Luke C. Multiple primary cancers of separate organ sites: implications for research and cancer control (Australia). Cancer Causes Control 2005;16:475-81. http://dx.doi.org/10.1007/ s10552-004-8023-0

13. Kellen E, Zeegers MP, Dirx M, et al. Occurrence of both bladder and prostate cancer in five cancer registries in Belgium, The Netherlands and the United Kingdom. Eur J Cancer 2007;43:1694-700. http://dx.doi. org/10.1016/i.ejca.2007.04.011

14. Singh A, Kinoshita $Y$, Rovito, et al. Higher than expected association of clinical prostate and bladder cancers. J Urol 2005;173:1526-9. http://dx.doi.org/10.1097/01.ju.0000154700.80042.c6

15. Draisma G, Etzioni R, Tsodikov A, et al. Lead time and overdiagnosis in prostate-specific antigen screening: importance of methods and context. J Natl Cancer Inst 2009;101:374-83. http://dx.doi.org/10.1093/ inci/dip001

16. Welch HG, Albertsen PC. Prostate cancer diagnosis and treatment after the introduction of prostate-specific antigen screening: 1986-2005. J Natl Cancer Inst 2009;101:1325-9. http://dx.doi.org/10.1093/ inci/dip278
17. Bjerregaard BK, Raaschou-Nielsen 0 , Sorensen $M$, et al. Tobacco smoke and bladder cancer-in the European Prospective Investigation into Cancer and Nutrition. Int J Cancer 2006;119: 2412-6. http:// dx.doi.org/10.1002/iic.22169

18. Pitard A, Brennan P, Clavel J, et al. Cigar, pipe, and cigarefte smoking and bladder cancer risk in European men. Cancer Causes Control 2001;12:551-6. http://dx.doi.org/10.1023/A:1011291015233

19. Freedman ND, Silverman DT, Hollenbeck AR, et al. Association between smoking and risk of bladder cancer among men and women. JAMA 2011;306:737-45. http://dx.doi.org/10.1001/jama.2011.1142

20. Zeegers MP, Tan FE, Dorant $E$, et al. The impact of characteristics of cigarette smoking on urinary tract cancer risk: a meta-analysis of epidemiologic studies. Cancer 2000;89:630-9. http://dx.doi. org/10.1002/1097-0142(20000801)89:3<630::AID-CNCR19>3.0.C0;2-0

21. Salminen E, Pukkala E, Teppo L, et al. Bladder cancer and the risk of smoking-related cancers during followup. J Urol 1994;152:1420-3.

22. Dhote R, Thiounn N, Debre B, et al. Risk factors for adult renal cell carcinoma. Urol Clin North Am 2004;31:237-47. http://dx.doi.org/10.1016/i.ucl.2004.01.004

23. Herity $B$, Moriarty M, Daly L, et al. The role of tobacco and alcohol in the aetiology of lung and larynx cancer. Br J Cancer 1982;46:961-4. http://dx.doi.org/10.1038/bjc.1982.308

24. Terry $P$, Ekbom $A$, Lichtenstein $P$, et al. Long-term tobacco smoking and colorectal cancer in a prospective cohort study. Int J Cancer 2001;91:585-7. http://dx.doi.org/10.1002/10970215(200002)9999:9999<::AID-IJC1086>3.0.C0;2-H

Correspondence: Dr. Piotr Czaykowski, Department of Oncology \& Hematology, Cancer Care Manitoba, 675 McDermot Avenue, Winnipeg, MB R3E OV9; fax: 204-786-0196; piotr.czaykowski@cancercare.mb.ca 